\title{
Contestations of the meanings of love and gender in a university students' discussion
}

\author{
Sisa Ngabaza, Dominic Daniels, Olivia Franck and Rhulani Maluleke
}

\begin{abstract}
Love is a fluid and complex concept that is difficult to define comprehensively. Its expressions, however, show that love is not only gendered but also influenced by one's social and economic positioning. Family upbringing, friends, race, culture and religion shape and constrain experiences of love. Third year students in a women's and gender studies class carried out a qualitative feminist study to explore how university students understood rights and responsibilities in romantic love. In a class of 127 students, each student conducted two semi-structured interviews with two university students of either sex. The findings were discussed in class through a panel discussion steered by five students. The students' findings revealed that contextualised relational power issues, economic factors and the role of sex had importance in the way romantic relationships were understood. This Briefing presents the discussion in which multiple issues are raised on the dynamics of love among some university students, as they strive to find the meaning of romantic love.
\end{abstract}

\section{Introduction}

Given the high incidence of HIV and AIDS in South Africa and the rest of the continent, much attention has been paid to the unsafe sexual practices of young people. Within this context, the element of love, desire and relationships has not received much cover- age. Where it has, love finds association with materialism (Bhana and Pattman, 2010) and is also linked with power inequalities in transactional relationships (Masvaure, 2010; Shefer et al, 2012). Love is an abstract emo- tion which is difficult to understand or encapsulate in a single definition since it may mean different things to different people, across locations, time and culture. For exam- ple, love is seen as a union with somebody or something, outside oneself (Meyer, Moore and Viljoen, 2008). By contrast, it can also be viewed as a means by which commitment is achieved in a relationship and appears primarily in the context of the search for a long- term mate (Robert and Weis, 2006). It is also related to the psychological attraction of affection as well as passion (Borusiak, 2012). Whilst these authors define love as emotional, physical, and intimate, they do not say much about the contexts within which it occurs. Yet, these contexts, highlighted for example by Hunter (2010) writing about love in informal settlements in a time of HIV/AIDS, or love in the poverty of townships (see Bhana and Pattman, 2011), and how young men see love in relation to masculine identity (see Malinga and 
Ratele, 2012), or the negotiation between young women and men in transactional sex on a university campus (see Shefer et al, 2012) all serve to demonstrate the diverse ways in which love is socially moulded and shaped.

The South African constitution emphasises freedom of choice in matters of love and relationships, that is, people have a right to choose who to love and how to love them. Yet there are numerous tacit and salient constraints around how love should be performed and equally distinctions are made about how men and women love. The way people love and the choice around who they love remains largely defined by the dominant societal norms in the South African context. For example, one of the dominant expectations among some black communities in South Africa that reflects how courting is governed by conventions on appropriate gender norms is that men are expected to proposition women and women to accept (Malinga and Ratele, 2012). Another example which shows the gendered nature of love is that female love is often spoken of in relation to emotional love while male love is identified with physical love (Allen, 2003; Borusiak, 2012).

Students' understanding of love is anchored in their understanding of masculinities and femininities within the contexts in which relationships occur. Feminist theorists on gender and equality argue that we live in a world that is divided by gender and this division is inextricably intertwined with other facets of difference, including race, ethnicity, religion and class among others. As we engage in personal and interpersonal relationships we tend to be "rebuilding and maintaining the social order" (Lorber, 2010: 9). Choices about love and the subjects of desire are not only individual matters as our social environments in most cases influence and control these decisions (Walker, Reid and Connell, 2004). How young men and women understand love contributes to shaping the kinds of gender identities, masculinities (the diverse social practices of being men) and femininities (diverse social behaviour or practices recognised as 'feminine') at play in these relationships.

This Briefing reports on a Women and Gender Studies module in which 127 third year students conducted research into the rights and responsibilities of young people in romantic love. The research draws from a bigger project conducted by Women and Gender Studies at the University of the Western Cape, in collaboration with the Medical Research Council. The study drew on a qualitative framework, and employed feminist principles that highlight the role of the researcher and take into account notions of reflexivity in the research process. Data was collected through semi-structured interviews that were conducted with two university students of either sex, and used a feminist qualitative thematic analysis which paid particular attention to how participants constructed their own meanings of love from their stand point, that is as male and female university students. All students signed consent forms agreeing to the publication of data collected as part of the requirement of the module. Students presented the research findings during a class discussion that was steered by a panel of five 
students. During the discussion they also raised observations about what their participants understood as love.

\section{Young people's claims to love are contextualised and shaped by economic factors}

This Briefing presents themes that emerged from the class discussion where students shared and also reflected on their findings. The most important findings from the discussion of the students' research were that young people's claims to love are contextualised and shaped by economic factors. Gender, money, culture and sex were found to have a direct impact on "love" and its socially derived meanings. Further, the role of sex was significant in the way relation- ships were understood. It should be noted that two thirds of the class were female students and this is bound to reflect in the presentation of student voices below. Although there was reference to some participants being in same sex relationships, the students' discussion contested heterosexual relationships.

\section{Love, gender and money}

The students in the Women and Gender Studies class come from different class, cultural, racial and religious backgrounds. In discussing their participants' views on "love" they draw from these categories of difference to make meaning of the views. The students' narratives revealed that whilst love was a feeling, it was also simultaneously expressed physically and materially, in ways that were gendered, which made it complex. The following reflections on love and gender were raised by some of the students in the class discussion:

"My participants talked about race and culture but then the biggest [issue of difference] was gender. Especially, the guy I interviewed and the girl they were like 'put in a box' ... . and the girl said that she wants, she's more physical, she wants to express her emotions and she feels like she's in a box and that if she acts in a different way, it is wrong ... 'You are kind of put in that box that says this is your gender right, this is how you love.' That's one thing that came up a lot from my participants" (Female student).

“... they [interviewees] said that in the Bible men and women are different so men and women will definitely love differently" (Female student).

"The guy, for instance, he said that he did things like buy gifts for his girlfriend and all of that in order to show love. The woman said that it's more of an emotional thing"(Femalestudent).

"[to the question] how do they show love, both of them said being there for someone and caring for someone. So it also shows me that men can also be emotional even though most people say they aren't" (Male student).

The above quotes raise a number of issues on how gender intersects in various ways with love. The first participant draws from feminist theorising on gender to emphasise how men and women are expected to love differently. Although the 
participants do not practice love differently, and are sceptical of resisting, conforming to socially idealised standards of loving makes them feel as if they are in 'in a box'. In gender categorisation, men and women are in most cases expected to be different from each other and even to express their emotions differently (Allen, 2003), holding the essential qualities needed as Lorber (1994; 2010) has put it, to maintain the social order. In this instance the participant understands the normative or idealised ways of loving that are expected of a young woman as being constrained. Dominant discourses on love have tended to associate women and men in a binary where women's subjectivity and femininity is associated with emotion and men and masculinity, the opposite (Edley, 2001). In the above quotes the male participants care, and can therefore also be emotional, which challenges the gender binary.

In the South African context, among some black communities, certain prescriptions effectively demarcate what is expected of men and women in relationships (Malinga and Ratele, 2012). These prescriptions take the form of culture, religious belief and other social forms of expected behaviour and participants drawing from their own contexts underscore and make meaning of essentialist notions of loving, as seen in the allusion to the bible in another quote above.

The students' discussion of their research findings also linked love with materialism, (see Bhana and Pattman, 2011; Hunter, 2010; Jewkes and Morrell, 2012; Masvaure, 2010). In South Africa, male provider masculinity and culture intersect: the idea of a man providing for his loved ones is based on the understanding of what a man and woman's role is in a relationship. In most instances men are expected to uphold the role of being provider and the maintenance of provider masculinity often plays an important part in the power relations within relationships. At the same time women have associated contemporary provider masculinity with money and materialism and consumerism. The students' discussion of love suggest that the ideals of love remain strongly enmeshed within materiality (Sedikedes et al, 1994; Shefer et al, 2012).

“... my participant compared money and sex, he said if sex is dead in a relationship then it's like $\ldots 50 / 50$, it contributes $50 \%$ in a relationship so if that sex is dead, then there's no relationship. Because at the end of the day why must you be in a relationship if at night you won't have sex. And he mentioned that if he doesn't give money to the girlfriend, that girlfriend is expecting money, so if it's at the end of the month then that girlfriend is waiting ... at the end of the day if there is no money and there is no sex then what is the relationship about?" (Female dent).

The above quote reveals that in addition to emotional aspects of love, for some young men at university, the ability to provide financially and engaging in sex, were equally important parts of what constituted "love". The notion of love as a transaction intersects with provider masculinity, as has been highlighted by a number of authors (see Bhana and Pattman, 2011; Hunter, 2010; Masvaure, 2010; 
Sedikedes et al, 1994). Yet, providing has also been viewed differently in relationships where the ideal of giving meant there was mutual benefit for both the provider and the partner (Jewkes and Morrell, 2012). Although these sex/ money exchanges have been generally viewed as commodification of love, Hunter (2005) cau- tions that these transactions could be certain ways of showing investment in love and acknowledging the material realties in the lives of those involved. For example, in the above quote the participant emphasises that the partner would be waiting for money. If he does not provide and there is no sex then there is no relationship for both. It therefore remains problematic to separate romantic love and provider love as in some instances this can also be a way of showing commitment to the relationship. Providing as a way of fostering a relationship is further evident in the following quotes which still underline the provider masculinity, but also show contestations around the essential nature of providing in relationships:

"The guy for instance he said that he did things like buy gifts for his girlfriend and all of that in order to show love" (Female student).

"One participant said that she is afraid that the boyfriend can leave her so she's giving him money so that he does not leave her ... she is more like punishing herself" (Female student).

There was a strong reaction from the students who thought that the participant's partner was sponging money off her, since provision of money is accepted as a male responsibility in many cultures (see Hunter, 2010; Sideris, 2005). Some of the students found it problematic that the participant could know that she is loved when she does not receive money. In this case the students' discussions resonated with the earlier participants' idea of provider masculinity as the dominant gendered notion of what it means to be loved. Below are some of the reflections by the students on what their participants raised:

"I think what you said about the participant is that she is giving him money because she is scared he could leave her? So how does she know that she is being loved? How does she feel that she is loved? Cause if she is doing like things for him? You know - how is she getting love? You see now what is he actually doing? I think it is sad that you are trying to keep the relationship together and what is he doing? Is he playing his role?" (Female student).

"But what if it was different then? Because I do not think we would react as much if he was giving her money instead. Can't they feel the same love even if she is the provider?" (Female student).

In the discussion one female student used an example of students staying together in residences, and this was followed by a host of views from the students on this matter. She said that the practice by some females who are financially better off to give money to their boyfriends is not new: 
"This person, you are staying with him in residence. You do have money and he doesn't have [money]. Maybe like on the basis of allowance, I get like a R1 ooo from home and then he doesn't even get a cent and I've got The National Student Financial Aid Scheme of South Africa (NSFAS) and I've got all of these. Then at the end of the day then, I feel ok, if he doesn't have money then let me just give to him. Because I mean, we are students, I'm helping because I'm in love with the guy and I don't want him to go and get money from somewhere else” (Female student).

"Some people are willing to do this [give boyfriend money] if this is going to keep him. I am going to do it” (Female student).

"You know it really goes back to social constructions about what men are supposed to do... Men are supposed to give women money. [So] Why can't we as women do the same thing. What's the big deal?” (Female student).

"I'm not saying that we as women shouldn't give men money, I'm trying to say that it conflicts, if he is sponging on you and I'm constantly giving him money so that he can stay with me then it's a different story. But if it's in a different context or situation, then ok. The fact that she said that she is scared that he will leave her if she doesn't give him money, that is the thing" (Female student).

"A man must not sponge money off you. If a man is sponging money off you then get rid of him ... because love is the way out for him" (Female student).

Love and gender inequalities are often tied to women's subordination in relationships. The students argue that women seem to be accommodating a new form of subordination by investing in love. Empowering women to be agentic has often hinged on restraining men and this has failed to take cognisance of women's emotional agendas. In some cases women have surrendered their power in order to be seen as good women (Jewkes and Morrell, 2012). In this case the participant's performance of love is against the gendered norm of male provider and she does this to take care of her own emotional agenda, that is fear of rejection. Her vulnerability to exploitation does not make her a better woman and she is expected to uphold "conservative femininity" (Jewkes and Morrell, 2012: 1736). The discussion also links gender power relations and the gendered nature of providing within a relationship. Through contesting the participant's stance, the students are reproducing gender norms around femininities and masculinities; they are 'gendering activities' (Ratele et al, 2010). Instead of seeing agency, the students seem to be foregrounding exploitation. In this way they are rejecting the possibility of an equitable transactional relationship that could also possibly be nonexploitative (Shefer et al, 2012).

Contestations of gender roles abound in South African scholarship (see Sideris, 2005; Ratele et al, 2010) and these are in many cases framed around the normative ideals of loving. Students in this case are in essence contesting normative ways of loving. It is ideal that men provide as they are expected to be providers. Conversely, a 
female providing is exploitation even if the providing is done for the same reason that men do, that is to maintain a relationship.

While some students indicated that money was not significant in love, others strongly felt that love and money played a centrally important role in understanding the meaning of love. They questioned and probed the meaning of love drawing from their understanding of the gendered constructions of male and female roles in social contexts. Students argued that these gendered social constructions were even noticeable in their own reflections on what love is, as shown in the above discussion. However, over and above the student's views on gender norms, class and money remained fundamental in determining who participants could or could not love:

"When I asked my participants who can't you love? The first answer I got was someone who is not working, who is a kasi [township] guy .. . meaning that as a university student most ladies fall in love because they want to up their standard because of peer pressure... So money does play a role in the way that we view love - money has an influence on love" (Female student).

The significance of money and materialism as shown in the above extract is also layered with notions of class, when the participant indicates that as "a university student" (which denotes a better class) she cannot date "an unemployed township guy". The relationship between love and the aspiration to escape township poverty is equally emphasised by Bhana and Pattman (2011) and also Shefer et al (2012).

\section{The intersection of love, culture, race and religion}

The students' discussions also showed that it is problematic to talk about the meaning of love outside of a cultural context. Love remains a contestation of everyday cultural beliefs that are materially significant (Hunter, 2005). As Hunter suggests, culture is dyna- mic and varies over time and space, and exists in diversity of social beliefs and customs. Students' findings emphasised that love is influenced by culture:

"The way that we view love is relative from person to person. So I thought that the way a person defines love is also influenced by one's social, cultural and economic way of life" (Male student).

"What really interested me was the way our cultures can actually have an impact on the way we love and who we love..." (Female student).

Students underlined how cultural positioning played a role in influencing who people loved and how they performed love. Parallel to culture, participants also drew from religion and moralistic values to understand the meaning of love. Cultural and religious integration have been used around the construction of normative ideals of loving (Harrison, 2008), and this framing shaped how the participants understood the meaning of love. In some religions women's gender 
roles are so circumscribed that romantic love, in the widely held western sense, does not surface as important:

"My participant indicated that culture does have an impact on the way people love, because in some cultures you are not free to love or to choose who you want to love. She makes an example of some Indian cultures where people, whoever they need to marry and whoever they need to love, are chosen by their family ... . it's like she is not free to love, she is not free to choose who she can love" (Female student).

"You do what your husband tells you to do and you are just a submissive wife ... In our culture, Islam forces you to be submissive to your husband, do what he asks you. My question is, is there really love there? Because this is what your family wants from you, this is what your culture, your religion requires of you so where is the love because if you are just being submissive and listening the whole time I don't really see how the love flows because this is something that is required, where does it grow?" (Female student).

“.. . she [a student's interviewee] feels that sometimes they can't really act in the way that they want to because they know they are being watched or maybe their pastor is sitting by them. So they feel that maybe somehow religion limits them" (Female student).

“... their [interviewees] whole under- standing of what love is, their definition of love and how they performed it, was informed by the fact that they are religious people" (Female student).

Connections were also made between love and race and in this way participants continued to underscore how love is framed by the different context within which it occurs. It needs to be highlighted that in apartheid South Africa interracial relationships were not allowed but with the new democratic dispensation people have the right to love who they want to. The racialisation of love is still prevalent today (see Pattman and Bhana, 2010; Soudien, 2007) as the students found.

“... it's difficult if you are going to marry a white person as a black person, you know you have to sort of negotiate the different cultures that you have to deal with which would then impact on who you do love" (Female student).

The student discussion situated love within the broader gendered environment and reflected how the research participants' under- standing of love was mediated by religion, culture and race.

Students concluded the discussion by discussing how best to define love, drawing from their data. They found it necessary to deconstruct the notion that love is 'pure', that rather it is given gendered meanings by men and women within social and cultural contexts. The complexity of love was evident in the intersectional relationship of love with gender, money, sex and culture (Bhana and Pattman, 2011). 
It is in the deconstruction of dominant discourses of love, sex and at the different contexts, ideas and definitions of love may become apparent. Students attempted to deconstruct love in the following reflections:

"What if we take away this whole aspect of sex and money? What then do we have left?" (Female student).

"If we take away money and sex then there isn't real love... I know that every- one has their own definition of love..." (Male student).

“... what is love? ... When we were reading the literature for this course .. . it reduced love to sex. And again we are also reducing love to materialist things .... Unless we also find what love is again, like we take away those things, what do we have left? What is love besides that? What is the purpose of love for example? What is it besides that? ... What is it? Why is it that she is afraid that he won't love her anymore, it is all these things" (Female student).

The students' discussions raised the problem of talking about love without addressing the impact of the social and cultural contexts within which its meanings continually shift and how this occurs in complex ways.

\section{Conclusion}

This Briefing raises a number of issues on how young men and women understand the meanings of love. Whether there should be a distinction between how men and women love was an important concern in the students' discussion of love. The discussion pointed to the gendered nature of love as students considered the different ways in which love should be performed by men and women. Whilst the notion of men as provider was easily accepted, the idea of a woman providing was met with intense contestation and seen as exploitation. This contest raises further questions that may need exploration on whose right it is to provide. How are young men and women expected to perform love in contexts that are not only gendered but constrained and mediated by culture? In this discussion students also tacitly produced gender as they defended what they believed to be the ideal ways of performing love in front of their colleagues. The discussion also high- lighted that among university students it was difficult to talk about love without talking about sex and the transactional nature of romantic relationships. Some students flagged that they understood providing and engaging in sex as constituting love but such notions have been associated with inequalities and female subordination. Perhaps there is a need to engage students in consciousness-raising debates so as to deconstruct some of the idealised notions of performing love that promote inequality in relationships and in society.

In this space students were able to highlight the multiple constraints and challenges encountered by young people like themselves in attempting to perform love within the provisions of a liberal constitution. The students found it challenging to talk about and seek to understand how love should be understood or performed outside a social context. The way people love and the choice around 
who they love remains largely defined by the dominant heteronormative societal norms in the South African context. Perhaps there is a need for more debates on how young people understand romantic love as this understanding in- forms the femininities and masculinities at play in their personal and interpersonal relationships, and ultimately broader social values.

\section{Acknowledgements}

The authors would like to thank Prof Tamara Shefer, Prof Kopano Ratele and Associate Prof Lindsay Clowes for their role in conceptualising the broad project from which this briefing draws. The Women and Gender Studies class of 2012 is also applauded for their work. 


\section{References}

Allen L (2003) 'Girls want sex, boys want love: Resisting dominant discourses of (hetero) sexualities', in Sexualities, 6, 2, 215-36.

Bhana D \& Pattman R (2011) 'Girls want money, boys want virgins: the materiality of love amongst South African township youth in the context of HIV and AIDS', in Culture, Health \& Sexuality, 13, 8, 961-73.

Borusiak L (2012) 'Love, sex, and partnership: The orientations of college students in Moscow', in Russian Education and Society, 54, 8, 36-71.

Edley N (2001) 'Analysing masculinity: Interpretative repertoires, ideological dilemmas and subject positions', in SJ Yates, S Taylor \& M Wetherell, (eds) Discourse as Data, London: Sage Publications.

Harrison A (2008) 'Hidden love: Sexual ideologies and relationship ideals among rural South African adolescents in the context of HIV/AIDS', in Culture, Health \& Sexuality, 10, 2, 175-189.

Hunter M (2005) 'Cultural politics and masculinities: Multiple partners in historical perspectives in KwaZulu-Natal', in Culture, Health and Sexuality, 7, 8, 209-223.

Hunter M (2010) Love in the Time of AIDS: Inequality, Gender, and Rights in South Africa, Bloomington: Indiana University Press.

Jewkes R \& Morrell R (2012) 'Sexuality and the limits of agency among South African teenage women: Theorising femininities and their connections to HIV risk practises', in Social Science \& Medicine, 74, 11, 1729-1737.

Lorber J (1994) 'Night to his day: the social constructions of gender', in L Richardson, V Taylor \& N Whittier, (eds) Feminist Frontiers, Boston: Mcgraw Hill.

Lorber J (2010) Gender Inequality: Feminist Theories and Politics. New York: Oxford University Press. Malinga M \& Ratele K (2012) 'Love and the construction of young black masculinities', University of South Africa (UNISA), available at: http://www. inter-disciplinary.net/critical-issues/wpcontent/uploads/2012/o7/malingaglpaper.pdf, site accessed 17 May 2013. Masvaure T (2010) 'I just need to be flashy on campus': female students and transactional sex at a university in Zimbabwe', in Culture, Health \& Sexuality, 12, 8, 857-870.

Meyer WF, Moore C \& Viljoen HG (2008) Personology from Individual to Ecosystem, South Africa: Heineman Publications.

Pattman R \& Bhana D (2010) 'White South African school-girls and their accounts of black girls at school and cross-racial heterosexual relations outside school', in Ethnicities, 10, 3, 371-386.

Ratele K, Shefer T, Strebel A \& Fouten E (2010) 'We do not cook, we only assist them: Constructions of hegemonic masculinity through gendered activity', in Journal of Psychology in Africa, 20, 4, 557-568.

Robert J \& Weis K (2006) The New Psychology of Love, USA: Westchester Book Services.

Sedikedes C, Oliver M \& Campbell W (1994) 'Perceived benefits and costs of romantic relationships for women and men: Implications for exchange theory', in Personal Relationships, 1, 5-21. 
Shefer T, Clowes L \& Vergnani T (2012) 'Narratives of transactional sex on a university campus', in Culture, Health \& Sexuality, 14, 4, 435-447.

Sideris T (2005) "YYou have to change but you do not know how". Contesting what it means to be a man in a rural area in South Africa' in G Reid \& L Walker, (eds) Men Behaving Differently, Cape Town: Juta \& Co Ltd.

Soudien C (2007) Youth Identity in Contemporary South Africa: Race, Culture and Schooling, Cape Town: New Africa Books.

Walker L, Reid G \& Connell M (2004) 'Sex and power in South Africa' in L Walker, G Reid \& M Conell, (eds) Waiting to Happen? HIV and AID 